\title{
Effect of Temperature and Relative Humidity on the Performance of Steamer using Computational Fluid Dynamic (CFD)
}

\author{
Eflita Yohana", M. S. K. Tony Suryo Utomo", Tommy Ivantoro ${ }^{\#}$, Zainal Arifin*, \\ Mohammad Tauviqirrahman ${ }^{\# 1}$ \\ ${ }^{\text {\#} D e p a r t m e n t ~ o f ~ M e c h a n i c a l ~ E n g i n e e r i n g, ~ E n g i n e e r i n g ~ F a c u l t y, ~ D i p o n e g o r o ~ U n i v e r s i t y, ~ I n d o n e s i a ~}$ \\ ${ }^{1}$ mtauviq99@gmail.com \\ ${ }^{*}$ Department of Mechanical Engineering, University of Sebelas Maret, Indonesia
}

\begin{abstract}
Generally, the tea factories in Indonesia are still using Panning to withering the tea leaves using a rotating heated cylinder. This traditional method will lead to pollution due to the presence of smoke resulted from the burning of logs for heated cylinder. Therefore, as an alternative the use of steamer is becoming popular now. The aim of this study is to determine the distribution of velocity, temperature and mass fraction of steam in a steamer which affect the quality of tea. The varying velocities of $33.22 \mathrm{~m} / \mathrm{s}, 43.22 \mathrm{~m} / \mathrm{s}$ and $53.22 \mathrm{~m} / \mathrm{s}$ are chosen. The computational fluid dynamics (CFD) based approach using finite volume method ANSYS is used. Based on the simulation results, it is found that the velocity of $33.22 \mathrm{~m} / \mathrm{s}$ for conditioning the room is the optimal value of withering the tea leaves. It is also found that the early steam concentration of 0.95 can be reduced significantly up to zero. These results can be a guideline to design the steamer in more effective way.
\end{abstract}

Keyword - CFD, mass fraction, steamer, temperature, velocity

\section{INTRODUCTION}

Generally, green tea factory in Indonesia are still using the panning method, which is withering the tea leaves by passing them in hot rotating cylinder. The heat comes from burning wood, burning pollution that may contain carcinogenic substances which are harmful to the health. In this study, the withering tea leaves are carried out using the steam coming from the boiler pressure of 2 bar. Then, the pressurized steam is piped up into the space steamer. Steamer is the development of a tool panning for withering the tea leaves. Steam is produced by the boiler gasoline-fuelled diesel or biomass. Inside the chamber, the pressurized steam conduit steamer which is connected with the steam nozzle, so that when it is sprayed with the initial pressure of 2 bar down, it reaches the equilibrium with the environment, that is, $1 \mathrm{~atm}$. Varying the rotational velocity steamer may get the most efficient in the process of withering. This study focused on the condition of temperature distribution and the mass fraction of steam in the steamer by using analysis of Computational Fluid Dynamics (CFD).

Upon receipt of shoots from the garden, the tea leaves were laid on the floor and stirred to reduce the moisture content carried on the leaves. Then the tea leaves withered by passing the leaves on the cylinder heat about 5 minutes or passed sometime in the hot pressurized steam. Withering process aims to turn the activity of the enzyme that would inhibit the onset of the fermentation process and lowering the water content to around $60-70 \%$. Tea leaf withering temperatures between $80-100{ }^{\circ} \mathrm{C}$, for less than $800 \mathrm{C}$ causes non-lethal enzyme activity, more than $1000 \mathrm{C}$ may cause damage to the leaf tea [1].

The aim of this work is to investigate the effect of temperature and relative humidity on the performance of a streamer using computational fluid dynamic (CFD). Several parameters are compared to find the best design for streamer based on operating conditions.

\section{ANALYSIS}

Equations (1)-(5) are used to analyse the cases studied here. Mass balance of a fluid element states that the rate of mass accretion on a fluid element is equal to the net mass flow rate into the fluid element". The stream which has a direction into the fluid element will increase the mass of the element and it has positive value. And vice versa is negative [2]. So the mass conservation equations can be formulated as follows:

$$
\frac{\partial \rho}{\partial t}+\frac{\partial}{\partial x_{i}}\left(\rho u_{i}\right)=0
$$

Newton's second law states that the change rate of momentum of fluid particle is equal to the number of forces acting on the particle. The rate of increase in the momentum of the $\mathrm{x}, \mathrm{y}, \mathrm{z}$ per unit volume of fluid particles in directions $\mathrm{x}, \mathrm{y}$, and $\mathrm{z}$ are written by the following equation [2]: 


$$
\rho \frac{D u_{i}}{D t}=-\frac{\partial p}{\partial x_{i}}+\rho G_{i}+\frac{\partial}{\partial x_{j}}\left[2 \eta e_{i j}-\frac{2}{3} \eta\left(\nabla \cdot u_{i}\right) \delta i j\right]
$$

The energy equation is derived from the first law of thermodynamics. It express that the rate of energy change of fluid particles is equal to the summation of the rate of increase of heat of fluid particles and the total work. It reads [2]:

$$
\frac{\partial(\rho E)}{\partial t}+\frac{\partial\left(u_{i}[\rho E+p]\right)}{\partial x_{i}}=\frac{\partial}{\partial x_{i}}\left(k_{e f f} \frac{\partial T}{\partial x_{i}}-\sum_{j} h_{j} J_{j}+u_{j}\left(\tau_{i j}\right)_{\text {eff }}\right)+S_{h}
$$

The equation used to complete the chemical elements. To predict the future of local fraction of each element, the General conservation equation as follows:

$$
\frac{\partial}{\partial t}\left(\rho Y_{i}\right)+\nabla \cdot\left(\rho \vec{u} Y_{i}\right)=-\nabla \cdot \vec{J}_{i}+R_{i}+S_{i}
$$

The method of calculating vapor diffusion flux toward the wall in a turbulent flow according to Fick's law as follows:

$$
\vec{J}_{i}=-\left(\rho D_{i, m}+\frac{\mu_{t}}{S c_{t}}\right) \nabla Y_{i}-D_{T, i} \frac{\nabla T}{T}
$$

Schmidt is a number with a value of 0.7 and a turbulent viscosity and vapor diffusion coefficient is in the mix [3].

\section{RESULTS AND DISCUSSIONS}

CFD method can simulate fluid flow, heat transfer, mass transfer, chemical reaction, mixed flow using CFDbased software. It predicts a phenomenon that occurs in a system or device.

In this study, the model used is $k$-e realizable with enhanced wall treatment. The fluid is incompressible with gas mixture of water vapor and air. Methods used is the second order upwind discretization schemes.

\section{A. Validation}

Validation is performed focusing on the phenomenon of condensation films to determine the temperature that condenses around the wall. The method used is $k-\varepsilon$ turbulence.

Geometry in the validation process of wall condensation films made following the simulation according to the journal [4]. With the same geometry is simulated, and the results are compared with the journal. Figures 1 and 2 are the computational domain and the geometry of the film wall condensation. After the making of the geometry, the generation process is carried out mesh shown in Figure 3. Meshing on geometry with a number of divisions are $57 \times 120$. Skewness obtained from meshing process is set at $5.18 \mathrm{E}-03$, so that the meshing is acceptable for skewness, which is smaller than 0.85 [5]. Figure 4-6 show the velocity, temperature and mass fraction of vapor with turbulence mode ofl turbulent k-epsilon realizable.

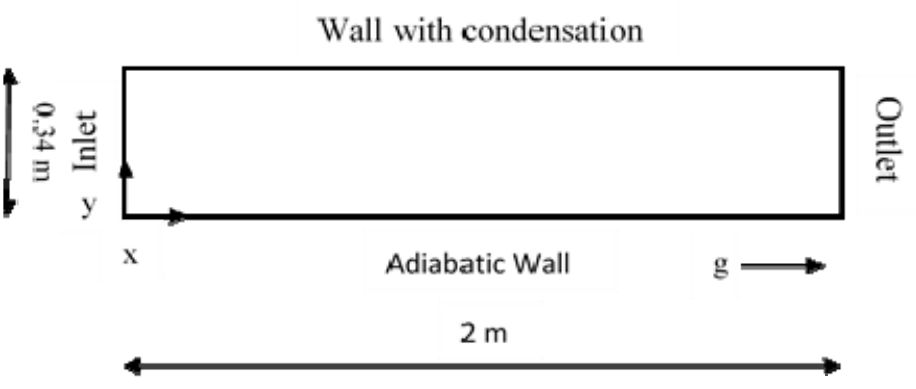

Fig. 1. Computational domain 
ISSN (Print) : 2319-8613

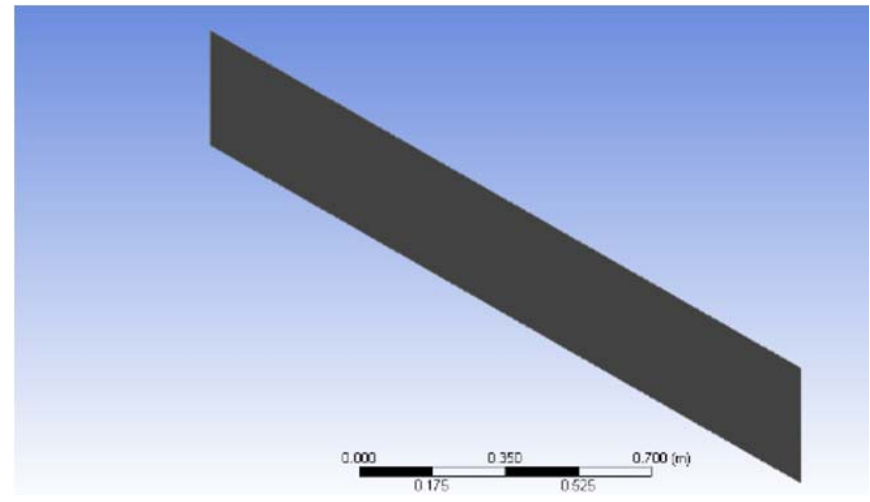

Fig. 2. Geometry of film wall condensation

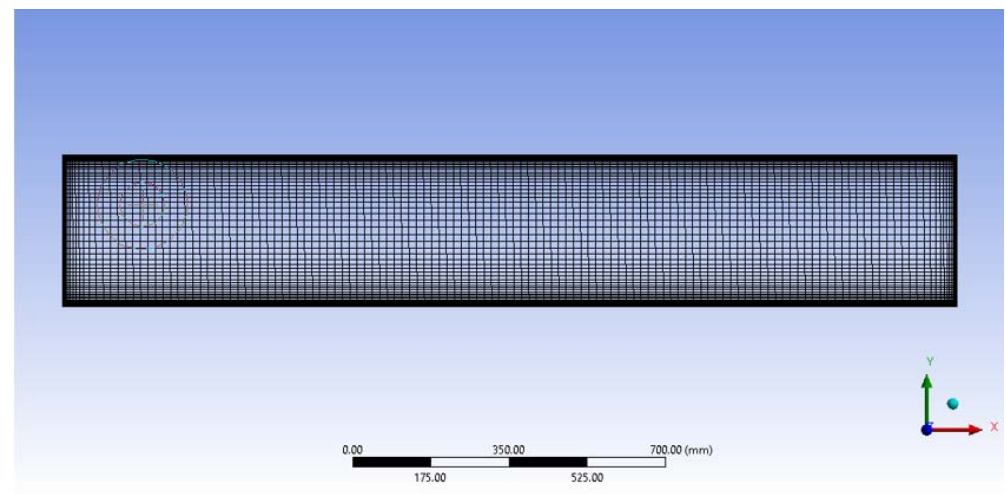

Fig. 3. Generated mesh

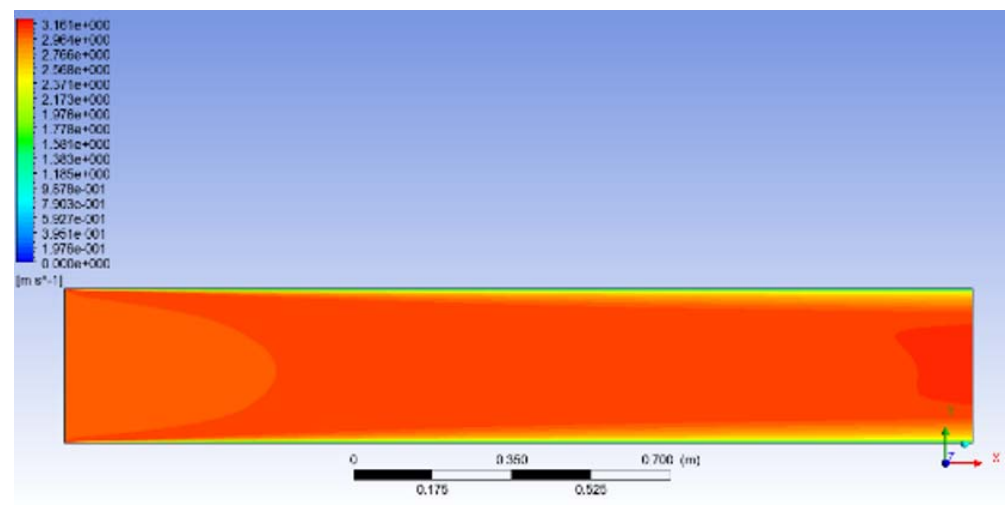

Fig. 4. Velocity contour

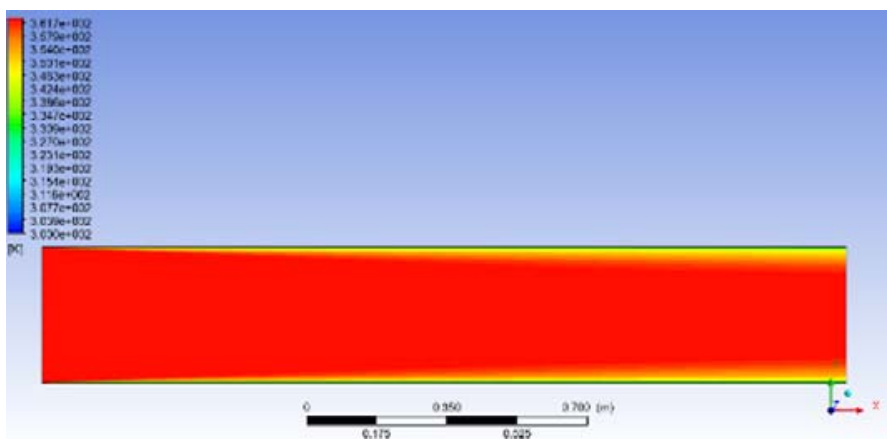

Fig. 5. Temperature contour 


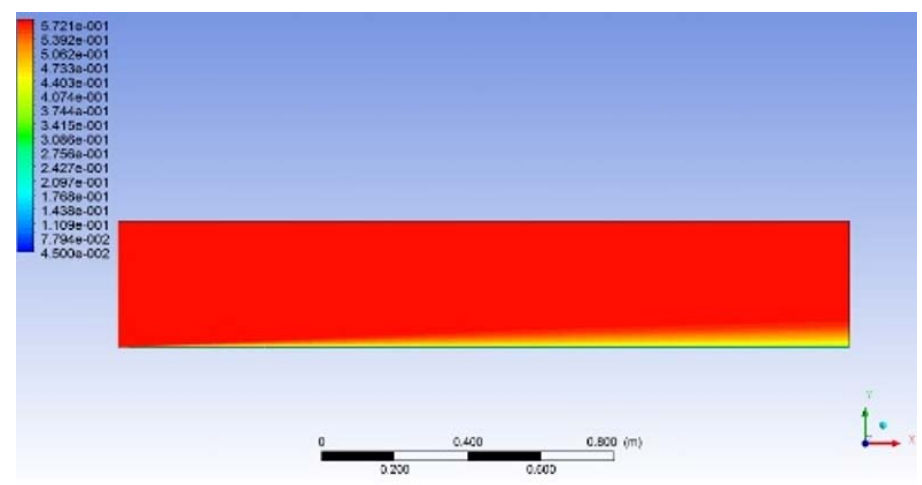

Fig. 6. The contours of mass fraction of steam

That temperature and mass fraction of steam are shown in Figure 7-9. The graph then compared to an existing chart in reference journals. The deviation is less than $20 \%$. With a maximum error on each chart velocity, temperature and steam mass fraction was $17.86 \%, 6.43 \%$ and $16.67 \%$. So the method in the journal can be applied in this study.

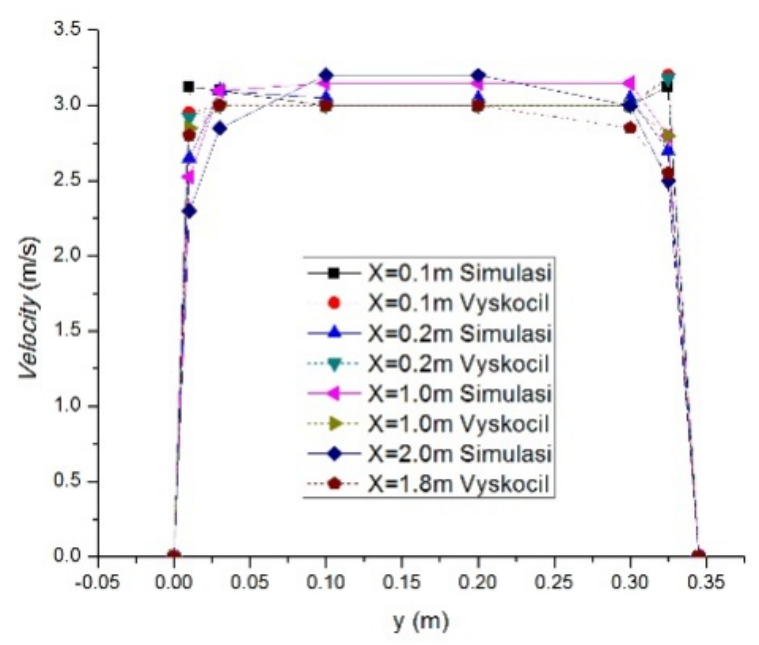

Fig. 7. Steamer assembly geometry and boundary conditions

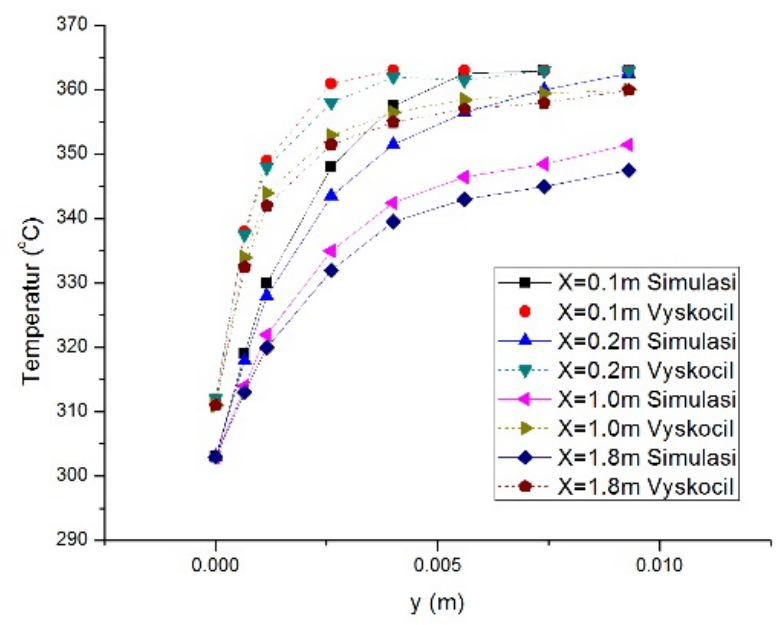

Fig. 8. Y-axis vs. temperature graph 


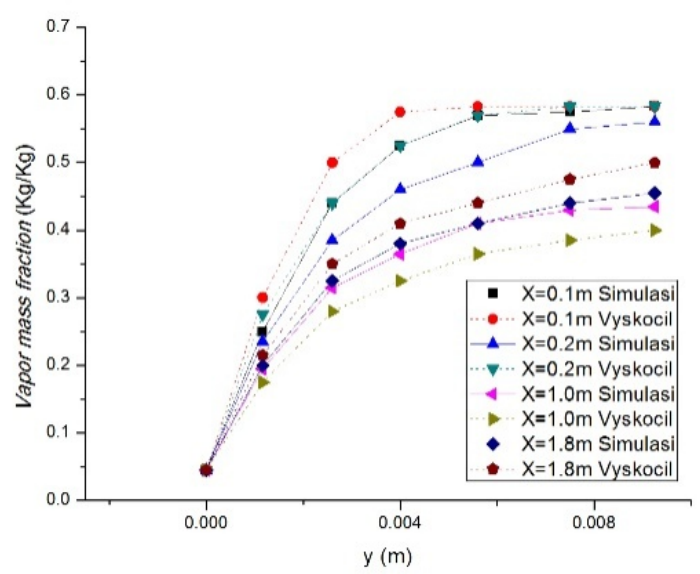

Fig. 9. Graph vapor mass fraction and the $\mathrm{Y}$ axis

\section{B. Effect of velocity}

Geometry has been performed in SOLIDWORKS with dimensions of $270 \mathrm{~cm} \times 90 \mathrm{~cm} \times 83 \mathrm{~cm}$ format stored .IGS and then It is simulated with CFD software. Figure 10 shows boundary conditions used in this study.

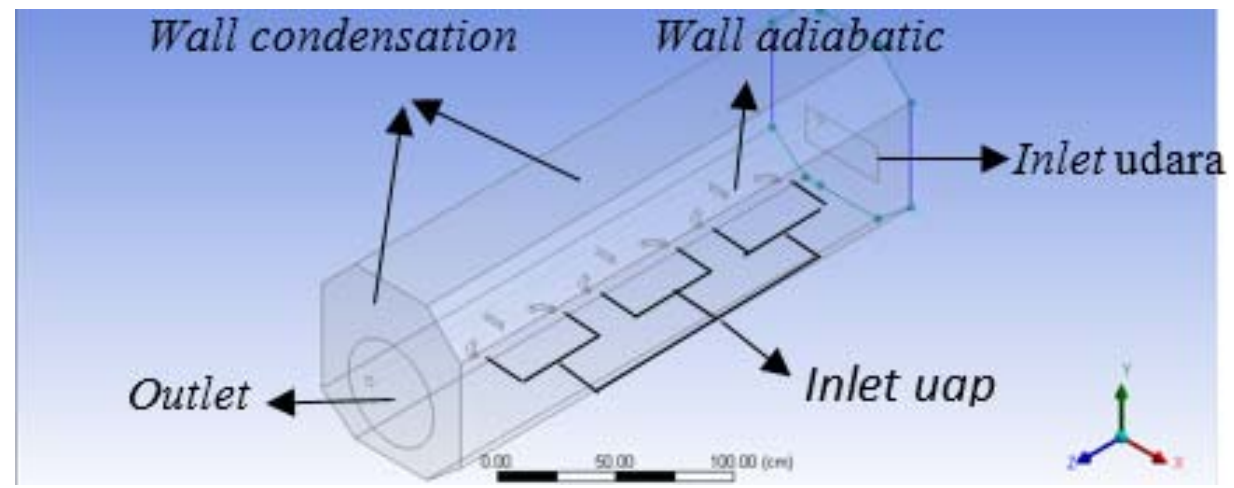

Fig. 10. Steamer assembly geometry and boundary conditions

The generation mesh is done in stages that make mesh on the overall geometry as shown in Figure 11. Then perform inflation on wall boundary conditions with maximum condensation layer 20 and a Growth Rate of 1.2 and at the outlet and inlet square in inflation with a maximum layer 5 and Growth rate 1.2. Then at the inlet have been treated with edge sizing of number of division by 30 and by growth rate of 1.2 as shown in Figure 12 .

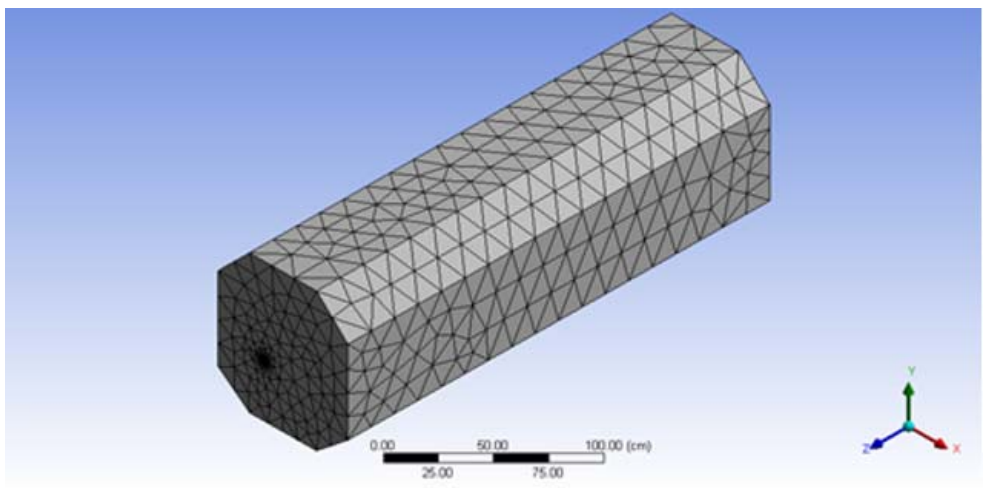

Fig. 11. Initial mesh 


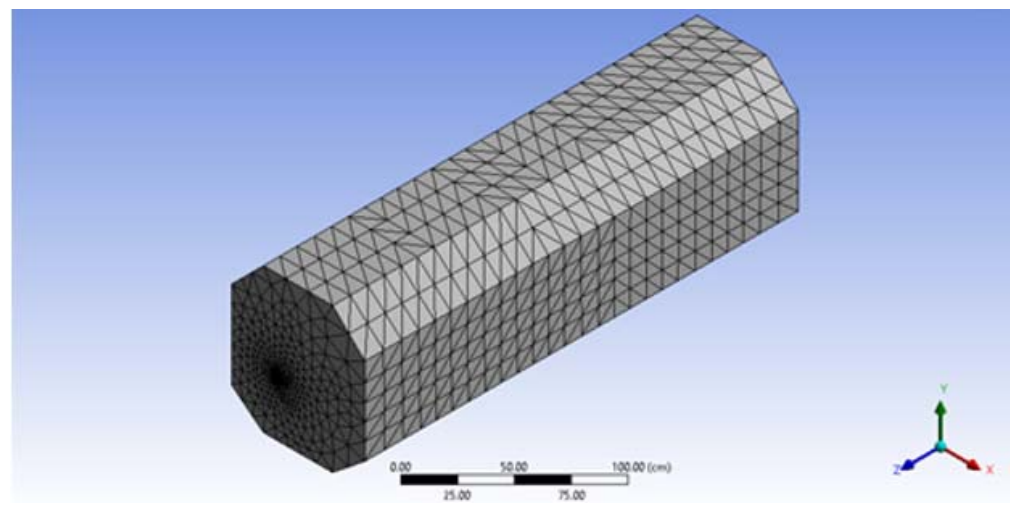

Fig. 12. Refined mesh

Tables I and II show the number of skewness and steamer model parameters, while Table III shows the boundary conditions for the phenomenon that occurs.

TABLE I. Grid and Skewness control

\begin{tabular}{|c|c|c|c|}
\hline No & Model & Grid & Skewness \\
\hline 1 & Steamer & 733600 & 0,81 \\
\hline
\end{tabular}

TABLE II. Parameter

\begin{tabular}{|c|l|l|}
\hline No & \multicolumn{1}{|c|}{ Parameter } & \multicolumn{1}{c|}{ Description } \\
\hline 1 & Multiphase & Mixture \\
\hline 2 & Energy & On \\
\hline 3 & Viscous & K-e Realizable \\
\hline 4 & Species & Species transport \\
\hline
\end{tabular}

TABLE III. Steamer Boundary Condition

\begin{tabular}{|c|l|l|}
\hline No & \multicolumn{1}{|c|}{ Parameter } & \multicolumn{1}{c|}{ Description } \\
\hline 1 & Velocity inlet & $43.22 \mathrm{~m} / \mathrm{s}$ \\
\hline 2 & Adiabatic wall & $97^{\circ} \mathrm{C}$ \\
\hline 3 & Condensation wall & $80^{\circ} \mathrm{C}$ \\
\hline 4 & Outlet pressure & $1 \mathrm{~atm}$ \\
\hline 5 & Density of multiphase & Incompressible ideal gas \\
\hline
\end{tabular}

The velocity distribution of temperature and relative humidity has an important role in the process of withering tea leaves. The tea leaves will wither on the conditions of temperature and the optimum mass fraction of steam. Figures13-15 describe the condition of velocity distribution in isometric view.

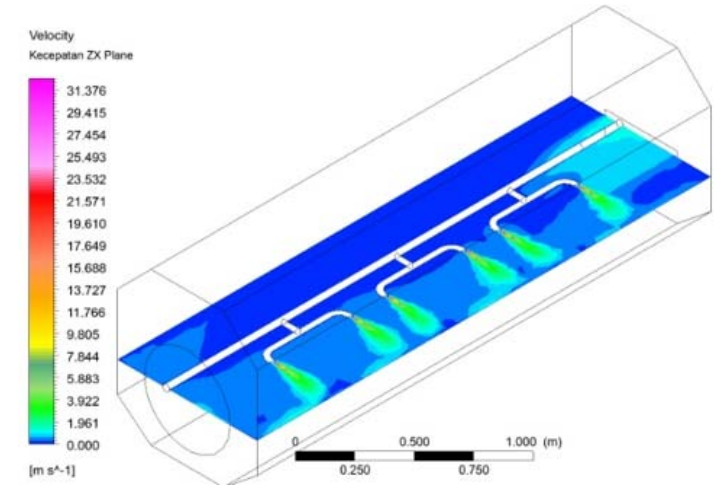

Fig. 13. Contour of velocity of $32.22 \mathrm{~m} / \mathrm{s}$ 


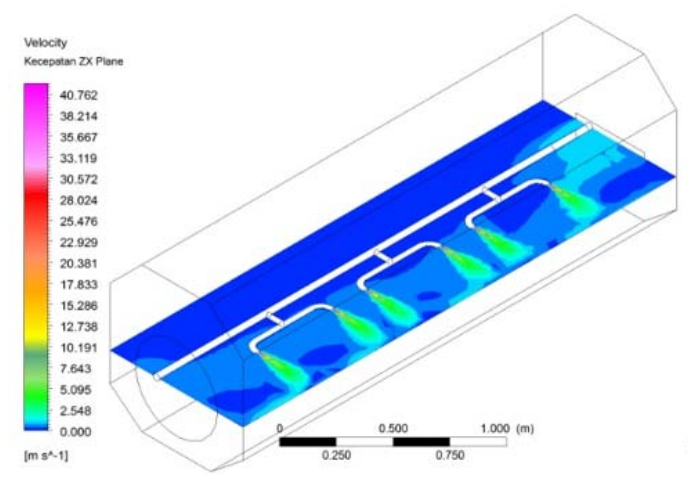

Fig. 14. Contour of velocity of $43.22 \mathrm{~m} / \mathrm{s}$

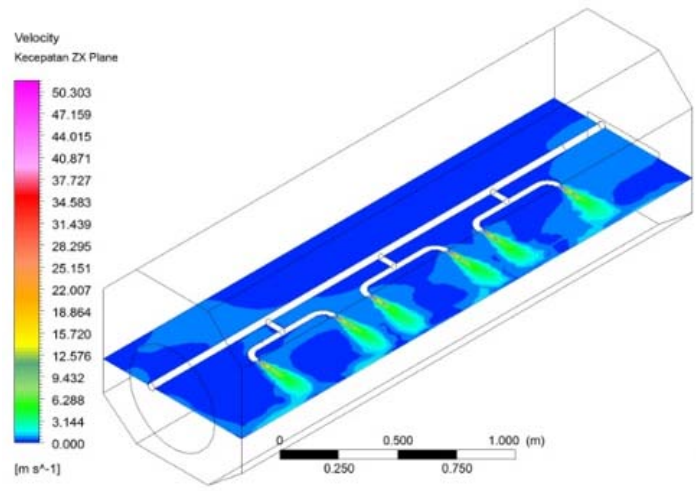

Fig. 15. Contour of velocity of $53.22 \mathrm{~m} / \mathrm{s}$

Based on Figures 13-15, it can be observed that the phenomena that occur in space steamer on the outlet nozzle have a tendency similar contour whatever the value of velocity. There is little difference when the velocity drops to below $3 \mathrm{~m} / \mathrm{s}$. Although the velocity contours looks the same, but each variation has a different value for the maximum velocity according to the amount of steam velocity. The phenomenon occurs because the velocity at each inlet hole is assumed to be uniform. In this simulation, the condition of the wall is also assumed to be slip, so that there is no influence of the steamer velocity on the wall. In accordance with [6], the steam mixture has a major role in the process of condensation. Inlet vapour velocity decreases abruptly toward the outlet of the mixing chamber. Again, according to [6] the velocity profile in a certain part of the mixing chamber has a tendency to have the same velocity.
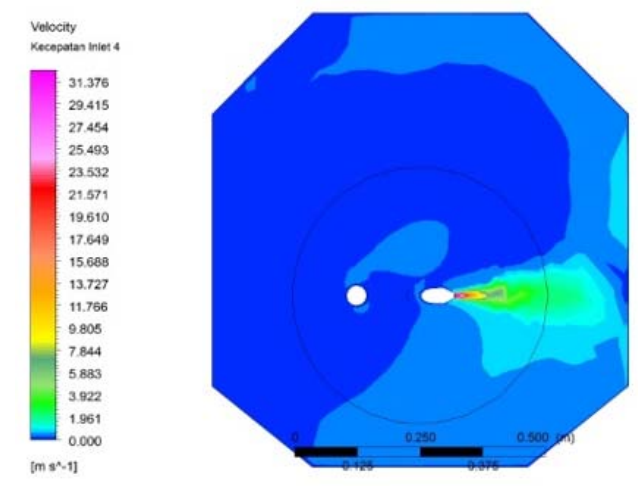

Fig. 16. Contour of velocity of $32.22 \mathrm{~m} / \mathrm{s}$ (in front view) 

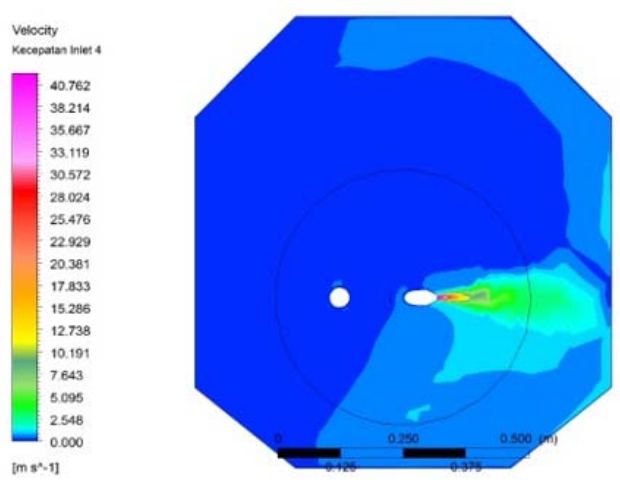

Fig. 17. Contour of velocity of $43.22 \mathrm{~m} / \mathrm{s}$ (in front view)
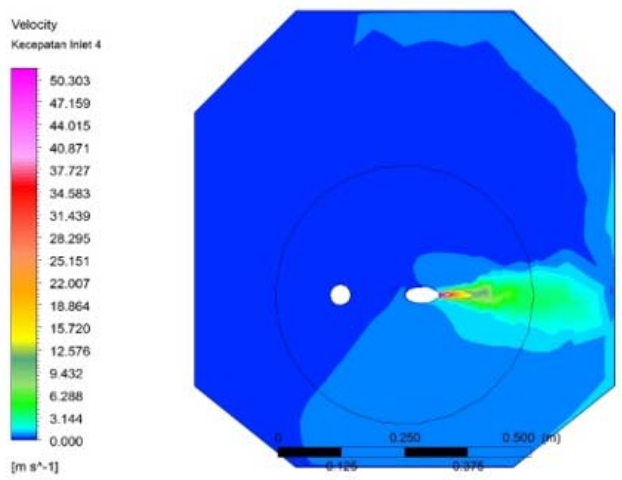

Fig. 18. Contour of velocity of $53.22 \mathrm{~m} / \mathrm{s}$ (in front view)

If the steam inlet compared to the large volume of steamer, then significant differences were seen for the inlet which has a diameter of $1 \mathrm{~cm}$ while the steamer size $270 \mathrm{~cm}$ x $90 \mathrm{~cm}$ x $83 \mathrm{~cm}$. This resulted in the entry velocity steam will immediately undergo deterioration. Figure 16 shows the entry velocity $33.22 \mathrm{~m} / \mathrm{s}$ at the inlet 4 where after the fluid in the form of steam out of the pipe, the velocity of which initially amounted to $33.22 \mathrm{~m} / \mathrm{s}$ and then decreased to less than $1,961 \mathrm{~m} / \mathrm{s}$. Similarly, in Figure 17 and Figure 18 shows the entry velocity $43.22 \mathrm{~m} / \mathrm{s}$ and $53.22 \mathrm{~m} / \mathrm{s}$ at the inlet 4 where after the fluid in the form of steam out of the pipe, the velocity of which initially amounted to $43.22 \mathrm{~m} / \mathrm{s}$ and $53.22 \mathrm{~m} / \mathrm{s}$ and then decreased to under $2.546 \mathrm{~m} / \mathrm{s}$ and $3.144 \mathrm{~m} / \mathrm{s}$. Figure 16-18 shows evidence that the contours of the temperature distribution around one inlet declined with the spread of velocity toward the right wall of the steamer ride gets up and gets down there below.

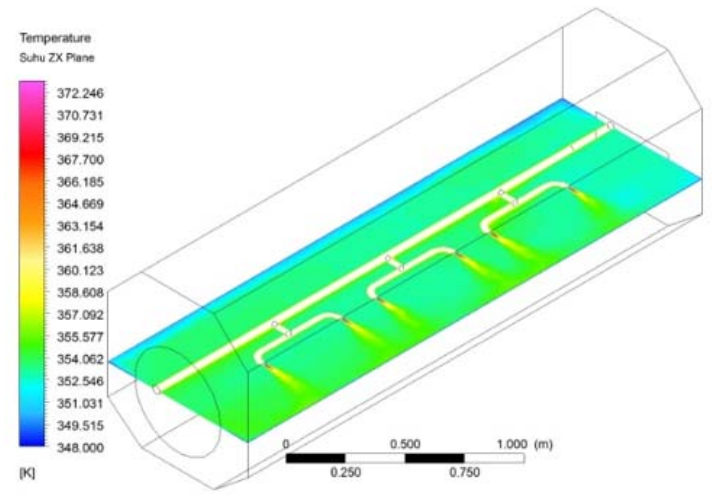

Fig. 19. Contours of temperature on the velocity of $53.22 \mathrm{~m} / \mathrm{s}$ 


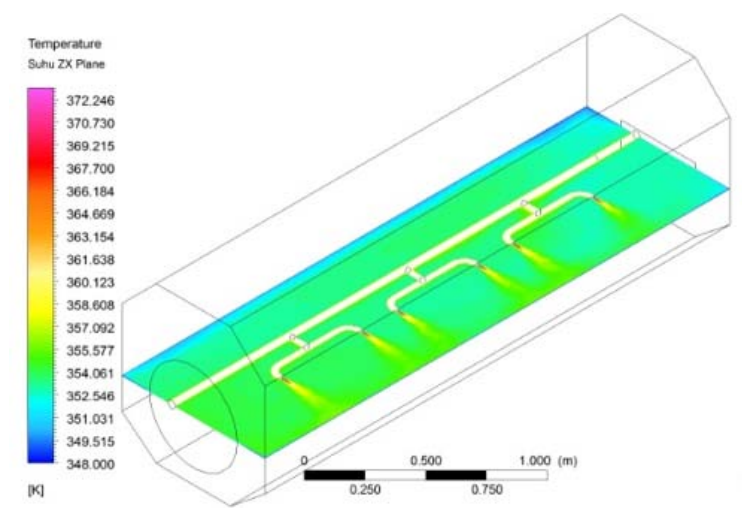

Fig. 20. Contours of temperature on the velocity of $53.22 \mathrm{~m} / \mathrm{s}$

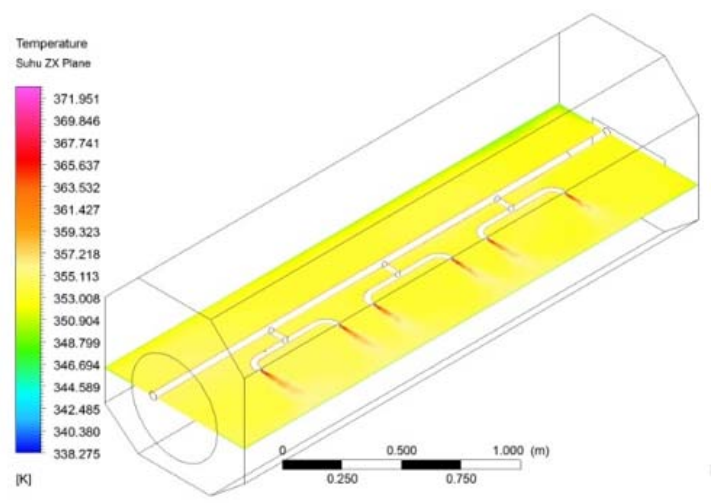

Fig. 21. Contours of temperature on the velocity of $53.22 \mathrm{~m} / \mathrm{s}$

Figure 19-21 visible steam pipe which has a 6 hole as the steam inlet and a diameter of $1 \mathrm{~cm}$. The steaming pipe with the saturation temperature conditions entering the steamer $100^{\circ} \mathrm{C}$. However, due to the influence of a large enough volume steamer and steam pipes are small, the decline in the temperature slowly like Figure 19 and 20. In addition, a decrease in temperature had caused the incoming air inlets feed from tea leaves. Unlike the variation of $53.2 \mathrm{~m} / \mathrm{s}$, temperature looks more evenly spreading. The decrease will be seen in the area around the wall. Then to the wall on a steamer condition is assumed to be $75^{\circ} \mathrm{C}$ ambient temperature steamer has a uniform distribution ranging between $75^{\circ} \mathrm{C}-100^{\circ} \mathrm{C}$. The outlet is assumed at $52^{\circ} \mathrm{C}$.
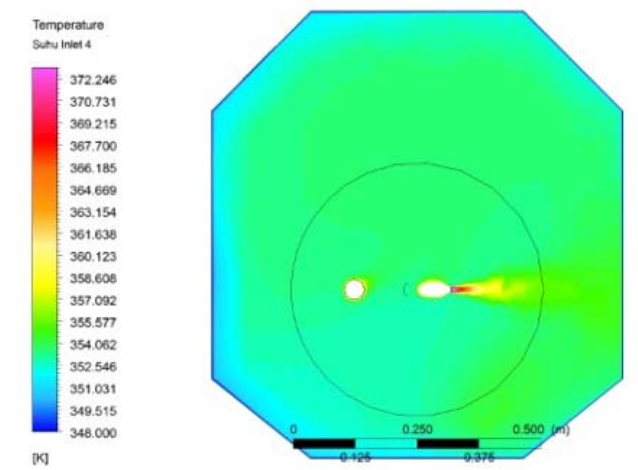

Fig. 22. Contours of temperature on the velocity of $32.22 \mathrm{~m} / \mathrm{s}$ (in front view) 

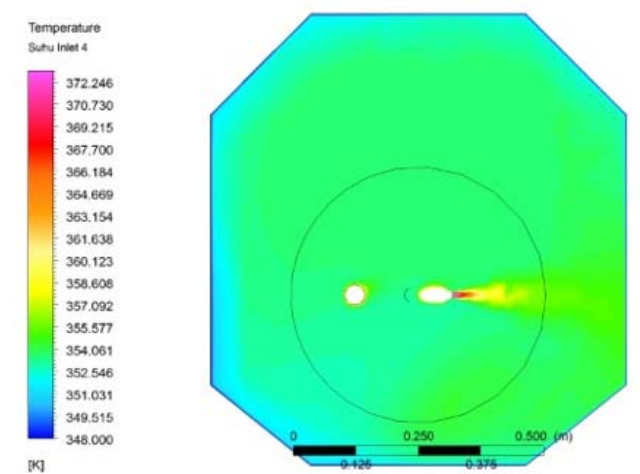

Fig. 23. Contours of temperature on the velocity of $43.22 \mathrm{~m} / \mathrm{s}$ (in front view)
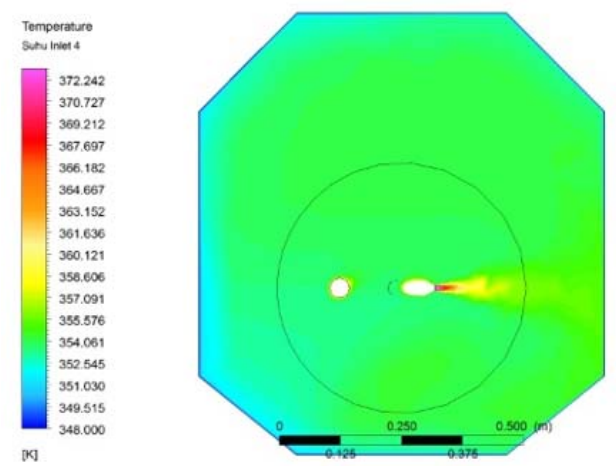

Fig. 24. Contours of temperature on the velocity of $53.22 \mathrm{~m} / \mathrm{s}$ (in front view)

On the third contour looks temperature distribution of temperature changes occur on the right side to the left side of the steamer. Based on Figure 22, the variation of velocity $33.22 \mathrm{~m} / \mathrm{s}$ contour displays the average temperature of $79{ }^{\circ} \mathrm{C}$. Figure 23 shows the variation of velocity $43.22 \mathrm{~m} / \mathrm{s}$ contour displays the average temperature of $80^{\circ} \mathrm{C}$. As well as for the Figure 24 variation of velocity $53.22 \mathrm{~m} / \mathrm{s}$ contoured average temperature is $81^{\circ} \mathrm{C}$. The results in accordance with [7] that the hot air that comes out of the inlet and into the drying chamber decreases the temperature which caused by the incoming air. With its optimal temperature, the steam produced in the steamer is able to wither the tea leaves more evenly.

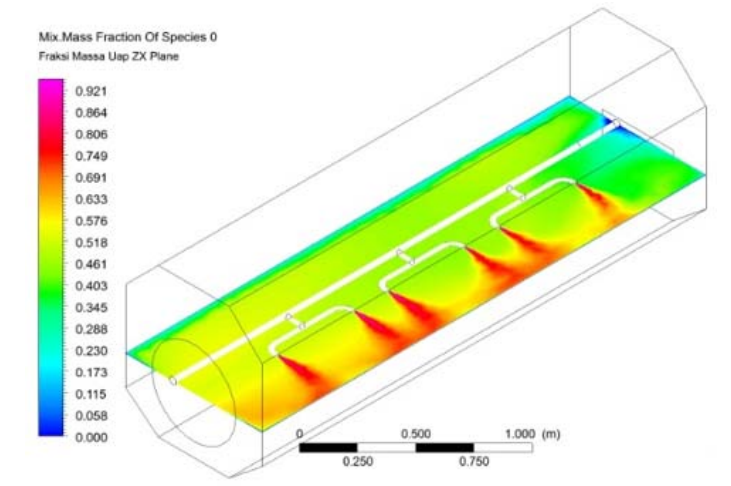

Fig. 25. The contours of mass fraction of steam to the velocity of $32.22 \mathrm{~m} / \mathrm{s}$ 


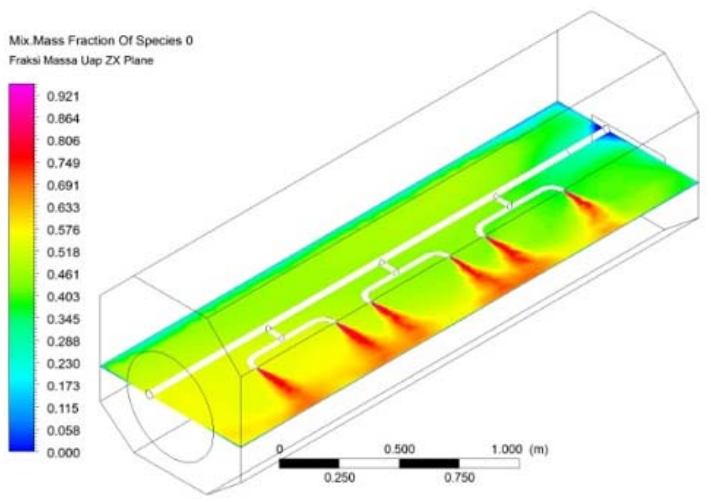

Fig. 26. The contours of mass fraction of steam to the velocity of $43.22 \mathrm{~m} / \mathrm{s}$

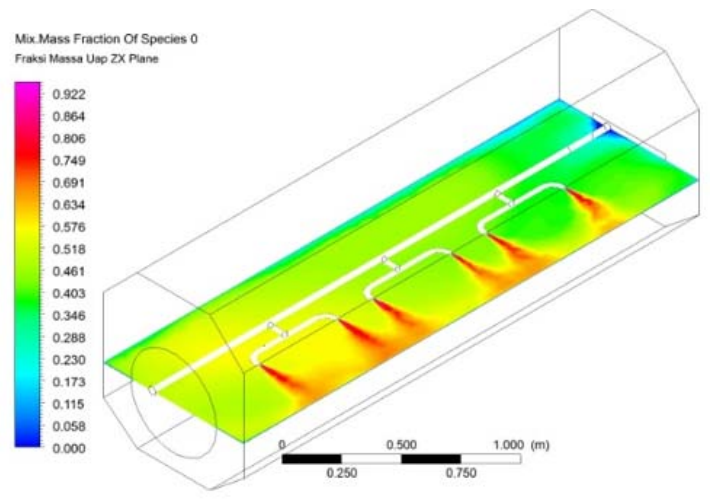

Fig. 27. The contours of mass fraction of steam to the velocity of $53.22 \mathrm{~m} / \mathrm{s}$

Figures 25-27 depict a mass fraction of steam after exiting the inlet. Along with decreasing the fluid velocity and temperature steamer, the mass fraction of vapour decreases. The mass fraction of steam which initially had a concentration of 0.95 on a scale of 1 , then decreased until it reaches a concentration of 0 . From the crosssectional contour difference is more visible at the inlet to the right side of the wall. Mass fraction of steam at a inlet velocity $33.22 \mathrm{~m} / \mathrm{s}$ is around 0.752 up to 0.95 with the highest intensity in the range of 0.810 to vapour mass fraction enters 43,22 velocity $\mathrm{m} / \mathrm{s}$ is around 0.691 up to 0.95 with the highest intensity the range of 0.749 and a mass fraction at entry velocity $53.22 \mathrm{~m} / \mathrm{s}$ is around 0.634 up to 0.95 with the highest intensity in the range of 0.691 . When viewed on a contour around inlet steamer it will be pink. The pink colour indicates a high concentration of vapour mass fraction. The conditions will be shown in Figure 28-30, which is a front view of a steamer on the variation of velocity $33.22 \mathrm{~m} / \mathrm{s} ; 43.22 \mathrm{~m} / \mathrm{s} ; 53.22 \mathrm{~m} / \mathrm{s}$.
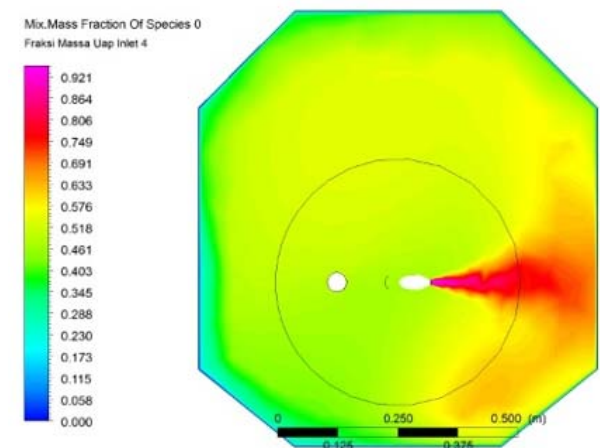

Fig. 28. The contours of mass fraction of steam to the velocity of $32.22 \mathrm{~m} / \mathrm{s}$ looks ahead 


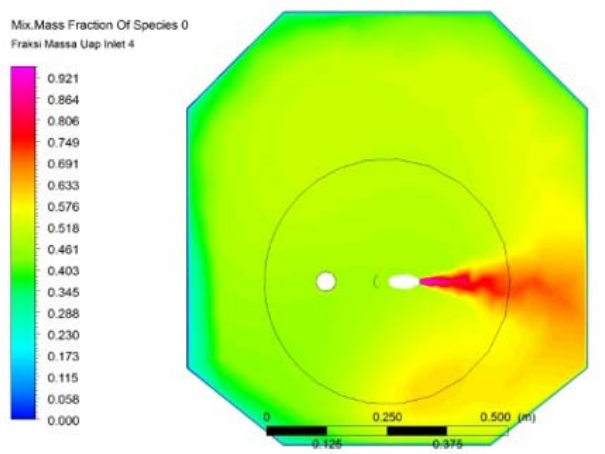

Fig. 29. The contours of mass fraction of steam to the velocity of $43.22 \mathrm{~m} / \mathrm{s}$ looks ahead

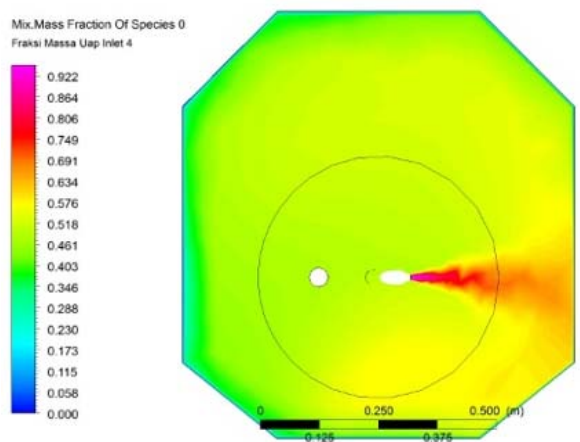

Fig. 30. The contours of mass fraction of steam to the velocity of $53.22 \mathrm{~m} / \mathrm{s}$ looks ahead

In accordance with experiments CONAN (Condensation with Aerosols and non-condensable gases) that do [4] a mixture of air and steam flow down past the square-shaped vertical channels. Where on one wall is cooled with water so that the steam condenses. Similarly, the simulation on PANDA Test 9 which two pressure vessels connected by pipes filled with air, and vapor ejected into the pressure vessel. When the amount of steam is released into a room and wall temperature is lower than the saturation temperature of the steam, the steam began to experience condensation. Obtained from the simulation contours show the mass fraction of vapor steam variation condition entry velocity $53.22 \mathrm{~m} / \mathrm{s}$. Entry velocity is directly proportional to flow rate. If the high flow rate, the steam coming out of the pipe will be more and more, this has resulted in rapid vapor condenses. Condensation process that is too fast will not lower the water content of the tea leaves so that the tea leaves do not wither. Therefore, the distribution of mass fraction at a velocity of $33.22 \mathrm{~m} / \mathrm{s}$ better than the velocity of $43.22 \mathrm{~m} / \mathrm{s}$ and $53.22 \mathrm{~m} / \mathrm{s}$ so that the tea products produced will be more vibrant.

\section{IV.CONCLUSION}

From the CFD results, it can be concluded that after the steam flows out the inlet pipe, the distribution velocity is not too different. Likewise for the temperature distribution, the difference in average temperature ranges between $5-10^{\circ} \mathrm{C}$. But unlike the mass fraction of steam, visible vapor mass fraction undergoes significant changes. Concentration decreases by 0.95 to arrive at a concentration of 0 .

When the three variations of velocity compared to the $33.22 \mathrm{~m} / \mathrm{s} ; 43.22 \mathrm{~m} / \mathrm{s} ; 53.22 \mathrm{~m} / \mathrm{s}$, temperature distribution contour with velocity variation $53.22 \mathrm{~m} / \mathrm{s}$ at a temperature higher than the space velocity variations $33.22 \mathrm{~m} / \mathrm{s}$ and $43.22 \mathrm{~m} / \mathrm{s}$ due to the temperature rise is directly proportional to the velocity. While the contours of mass fraction of steam in a steamer space can be proved that the velocity variation entrance $33.22 \mathrm{~m}$ / $\mathrm{s}$ distribution more equitable distribution of mass fractions in all sides of the room than the velocity variation $43.22 \mathrm{~m} / \mathrm{s}$ and $53.22 \mathrm{~m} / \mathrm{s}$. Overall it can be concluded conditioning space with entry velocity $33.22 \mathrm{~m} / \mathrm{s}$ has the most optimal distribution of distribution that will maximize the process of withering tea leaves to do the process at a later stage 


\section{REFERENCES}

[1] Hendrowidyatmoko, et al., Plantation Commodity Processing (Refreshing Beverage Ingredients), Inter-University Centre for Food and Nutrition. Yogyakarta; 1990

[2] H.K. Versteeg and W. Malalasekera, An Introduction to computational fluid dynamics: The Finite volume method, $2^{\text {nd }}$ Ed. Longman Scientific \& Technical. England; 1995.

[3] S. Hassid, "Turbulent schmidt number for diffusion models in the neutral boundary layer," Atmospheric Environment, Vol. 17, pp. 523-527, 1983.

[4] V. Ladislav, S. Josef, and M. Jiri, "CFD simulation of air steam flow with condensation," Nuclear Engineering and Design, Vol. 279, pp.147-157, 2014.

[5] A. Bakker, A., Applied Computational Fluid Dynamics, Lecture note; 2002.

[6] M. Bukurov M., S. Bikic, and P. Mijina, "The Efficiency Rate of a Steam-Water Injector," Acta Polytechnica Hungarica, vol. 9 , pp.107-126, 2012.

[7] M. Syaiful and Hargono, "Temperature profiles In the Agricultural Products Drying Process Simulation Computational Fluid Dynamics,” Reaktor, Vol. 12, pp.195-202, 2009. 